\title{
Novel Nanofibrous Scaffolds for Water Filtration with Bacteria and Virus Removal Capability
}

\author{
Anna Sato, ${ }^{1,2}$ Ran Wang, ${ }^{2}$ Hongyang $\mathrm{Ma}^{2}$ Benjamin S. Hsiao, ${ }^{2}$ and Benjamin $\mathrm{Chu}^{2}$ \\ ${ }^{1}$ Ward Melville High School, East Setauket, NY 11733 \\ ${ }^{2}$ Department of Chemistry, Stony Brook University, Stony Brook, NY 11794
}

With the rapidly increasing global population, climate change and pollution, the availability of clean water has decreased dramatically. The issue of shortage of drinkable water is no less urgent than that of oil and green energy [1]. Currently, over one billion people lack access to low-cost drinking water [2]. Thus, it is of paramount importance to develop efficient and cost effective water purification methods especially for the removal of bacteria and viruses [3]. There are many water purification methods, including filtration (size separation), adsorption, chemical coagulation, photodegradation, biodegradation, distillation, and active sludge, but filtration, especially microfiltration, is the most versatile chemical-free method, and it is extremely cost-effective, timesaving, and energy-efficient. A microfiltration membrane with a pore size ranging from 0.1-10 $\mu \mathrm{m}$ nominally is capable of retaining microbe-like bacteria larger than $0.2 \mu \mathrm{m}$ in diameter, but they are not suitable for removing viruses, which are often smaller in size by a factor of ten.

We report a promising method for producing porous membranes that are based on microfiltration but have capabilities for retaining viruses. The membranes consist of ultra-fine cellulose nanofibers $(\sim 5-10 \mathrm{~nm}$ in diameter) infused into an electrospun polyacrylonitrile (PAN) nanofibrous scaffold $(\sim 0.2 \mu \mathrm{m})$ on a melt-blown polyethylene terephthalate (PET) non-woven support (with $\sim 30 \mu \mathrm{m}$ fibers), Fig.1(a). These fi brous membranes exhibit excellent water filtration properties due to the controlled pore size to sieve bacteria, and the positive surface charge to adsorb viruses. The membane can achieve a simultaneous retention rate of $99.9999 \%$ for $E$. coli bacteria removal and $99.99 \%$ for MS2 bacteriophage virus removal in water while maintaining high flux permeation. High resolution electron microscopy investigation revealed, for the first time, the detailed nanoscale fibrous network in membranes that are responsible for these superior filtration properties. Fig.1(b-d) are SEM images showing that infusion of the $1 \mu \mathrm{m}$-long cellulose nanofibers creates a massive twodimensional complex interwoven structure with a pore size ranging from a few nanometers to a few hundred nanometers. The nanofibrous network is heavily entangled with the PAN scaffolds due to the effect of the diamine modification of the oxidized cellulose nanofibers and their cross-linking reaction with the scaffold. Examples of retention of E. coli bacteria and MS2 virus by the network are shown in Fig.2. These nanofibers help to adsorb viruses by charge through $\mathrm{pH}$ values (the isoelectric point of the MS2 was at a $\mathrm{pH}$ of 3.9). Because most viruses are slightly negatively charged, the electrostatic interaction between the positively charged nanofiber surface and the virus is attractive and adsorption occurs. The demonstrated membrane system opens a door to the further development of other nanostructured biomaterials to adsorb water pathogens and contaminants and increase the realization of the much needed inexpensive microfiltration membranes [4].

References

[1] J. Interlandi, “The New Oil”, Newsweek, Oct. 18, p. 40-46 (2010).

[2] World Health Organization, Meeting the MDG Drinking Water and Sanitation Target, Geneva, WHO, (2004).

[3] Y. Yoon, B.S. Hsiao, and B. Chu, J. Membrane Sci., 338, 145-152, (2009).

[4] We would like to thank. E. Kim, F. Wang, and N. Kikuchi for their assistance. This research was funded by the National Science Foundation through an EAGER grant (DMR-1019370). 

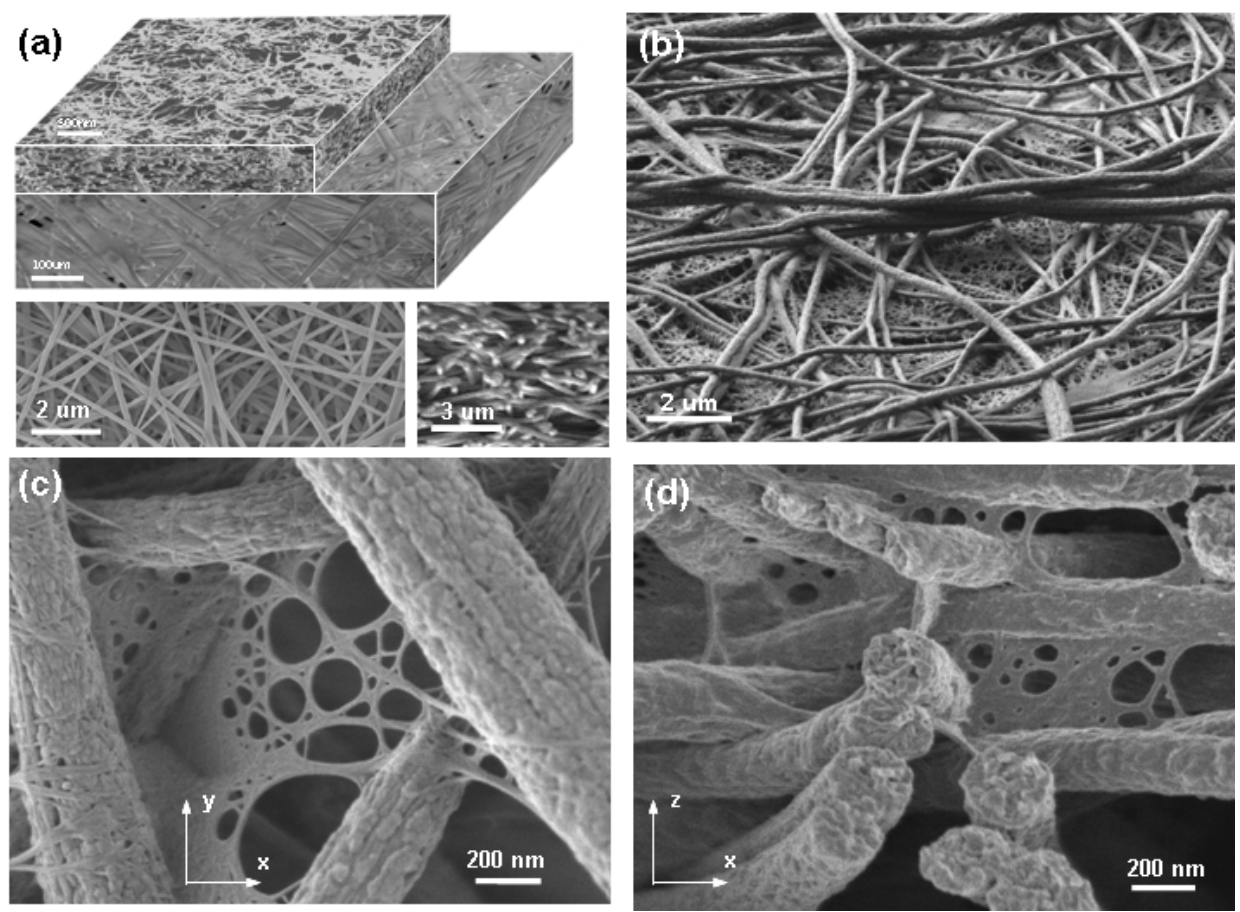

(a) The membrane assembly water filtration containing a two-layered structure: a non-woven substrate (with microfibers of $\sim 30 \mu \mathrm{m})$ as the bottom support, and a nan ofibrous scaffold $(\sim 0.2 \mu \mathrm{m}$ in diameter) as the top layer infused with ultra-fine cellulose nanofibers $(\sim 5-10 \mathrm{~nm})$. The top and side views of the scaffold are shown underneath. (b) Plane-view of the internal structure of the membrane $50 \mu \mathrm{m}$ from the top surface showing dense mesh formed by the ultra-fine cellulose nanofibers. (c,d) HR-SEM images of the membrane before bacteria and virus adsorption test (top and cross-section view, respectively) showing that the cellulose nanofibers are entangled with the scaffold to create a strong quasi three-dimensional network with various pore sizes ranging from tens to hundreds of nanometers.
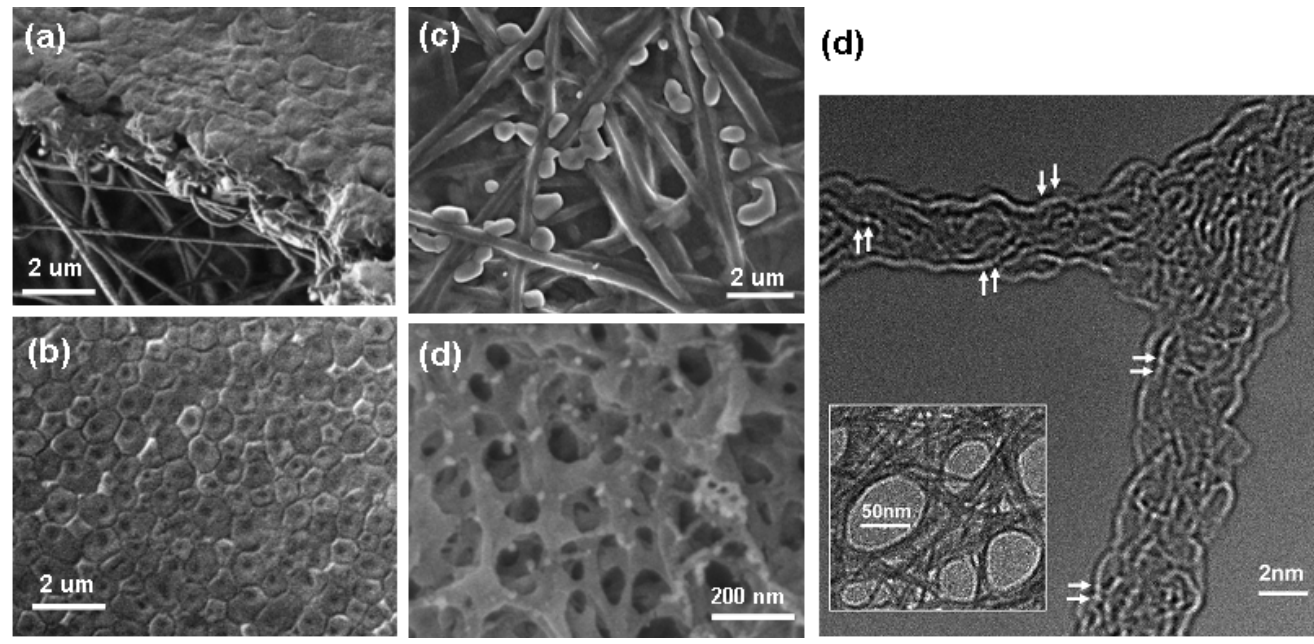

Fig.2 (a-d) SEM images of the electrospun membranes showing retention of E.coli bacteria (a-b and c are for high and low concentration of bacteria, respectively) and MS2 virus (d). The high concentration of E. coli bacteria forms a "cake layer" of honey-comb cells on the surface: (a) cross-section and (b) surface view. The white specks in (d) are MS2 virus $(\sim 30 \mathrm{~nm})$. (d) HR-TEM image of cellulose nanofibers taken at $80 \mathrm{kV}$ in an aberration corrected microscope. In the thin amorphous region, individual atoms (marked by the arrows) and polymer chains with spaghetti-like configuration are clearly visible. The inset gives an overview of the cellulose nanofiber mesh. 